\title{
THE ROLE OF COOPERATION AND TEAMWORK BE- TWEEN PEOPLE WITH DIFFERENT NATIONALITIES IN TRANSITION COUNTRIES
}

\section{Suada Ajdarpašić ${ }^{1}$ \\ Rialda Muharemi Edonis Buxhovi}

University "Haxhi Zeka", Faculty of Business
Original scientific paper

UDC:005.64

331.101 .64

Accepted: 21.02.2016

\begin{abstract}
A topic that tells a lot about us as human beings, about our abilities and virtues is the fact that shows and explains how much we are able to work together and make collective decisions in the operating process. How much people are willing to cooperate, plan, organize, coordinate, manage and control the situation, depends on many factors. In continuation of my work, I will explain how much people are willing to provide the support to their colleagues, friends and random people in teamwork when making decisions on a specific field, and also the cooperation process between the people on many stages in transition countries. This work comes down to personal study, where, I have based on the questionnaire dedicated to the students, academic and administrative staff at the different Universities and Secondary schools of Kosovo. What is their general perception about cooperation and teamwork, its quality, advantages and disadvantages, its reflection on success or failure, the significance of individual and collective decisions, current and future application of, friendships with other ethnicity, and many other issues, it is stated in the further work. According to the data collected it can be said that the interviewed people are familiar in a large \% with the process of cooperation, whether in a small group but also in a large group. However, why is it applied or not you will read throughout this paper.
\end{abstract}

Keywords: Cooperation, Students, Work, Group, Team, Organization, Decisions, Interview.

JEL Classification: C: C7, C9, C91, and C92.

D: $D 23$

\section{INTRODUCTION}

Almost every aspect of our lives, whether it is a government, business or community group, is increasingly relying on work teams to streamline processes, enhance participation, and improve performance. Teamwork, as the most effective form of cooperation, is of worldwide importance. So, individuals who wish to participate fully in community and professional life must increasingly possess the skills necessary to work in teams.

\footnotetext{
${ }^{1}$ Correspodence to:

Suada Ajdarpašić, University "Haxhi Zeka", Faculty of Business

Eliot Engel 30000 Peja, Republic of Kosovo

Phone: 0038649687970

E-mail: suada.ajdarpasic@unhz.eu
}

A team is a unit of two or more people who interact and coordinate their work and who cooperate constantly through communication to accomplish a specific goal. Through this kind of work members of the team have a great benefits; everyone has right to express their ideas, has right to make joint decisions i.e. everyone has equal rights, effectiveness and efficiency have stronger intensity, the entire process of cooperation brings better solutions for the specific problem. 
Teams come closest to achieving their full potential when they enhance individual productivity through increased member effort, member personal satisfaction, integration of diverse abilities and skills, and increased organizational flexibility.

To be successful over the long run, team must be structured so as to both maintain its member's social well-being and accomplish its task. In successful teams, the requirements for task performance and social satisfactions are met by the emergence of two types of roles: task specialist and socioemotional.

There are many factors that influence the success of teamwork. Therefore, factors that influence team effectiveness begin with the organizational context. The organizational context in which the group operates includes such factors as structure, strategy, environment, culture and reward systems. But, the most important team characteristics are the type of team; the team structure and team composition. Factors that can have a tremendous impact on team processes and effectiveness are factors such as the diversity of the team in terms of gender and race, as well as knowledge, skills and attitudes.

However, most teams go through systematic stages of development: forming, storming, norming, performing and adjourning. Therefore, team characteristics that can influence organizational effectiveness are size cohesiveness, norms and members roles. All teams experience some conflict because of scarce resources, ambiguous responsibility, communication breakdown, personality clashes, power and status differences, and goal conflict. But, there are still many techniques for resolving these conflicts including super-ordinate goals, barging, mediation and communication.

The entire process and the success of the teamwork depend on the proper management. Staff planning is a dynamic continuous process of which all managers should have a good understanding. This is because of the increasing complexity of organizations and activities; the ability of required expertise; technological changes and advances; labor turnover patterns; the structure of the workforce; the changing nature of labor markets; imbalances between the skills available and those required; the nature of core and peripheral workforces.

Teamwork, more than other life skills, is likely to be affected by culture. Although the team skills described in this paper are assumed to define teamwork generally. Interviewed people proved to be quiet positive. They showed a lot of understanding, but not enough knowledge of the methodological approach.

In essence, their approach to this form of work is with a very low intensity. There is a huge desire for the implementation of teamwork; however the circumstances are those that do not allow. One of the factors that affects on the poor utilization of this form of business is the mentality and culture of the people of our state.

\section{LITERATURE REVIEW}

Teamwork has traditionally been described in terms of classical systems theory in which team inputs, team processes, and team outputs are ordered over time. So that, team inputs include the characteristics of the task to be performed, the elements of the context in which teamwork occurs and the attitudes team members bring to a team situation. Team process includes the interaction and coordination among members required for performing team tasks and achieving specific goal. Team outputs consist of the products that result from team performance. With regard to teamwork, the process phase is the defining point at which teamwork occurs; it is during this phase that team members interact and work together to produce team outputs.

Example: An opponent in a game must be an uncontrolled factor. Otherwise, one would know exactly where the game was going and how it would end. And it would not be a game at all. Where one football team would be totally capable of controlling the other football team, we have no football game. This is a matter of "no contest". There would be no joy or sport in playing that game of football (Hubbard, 2007). 


\section{Input}
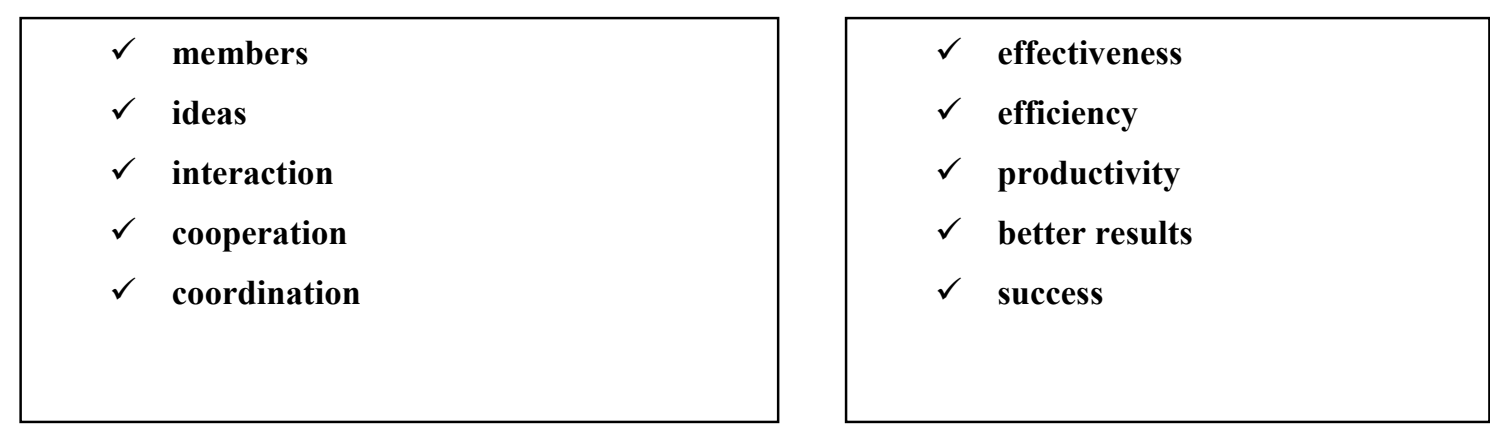

\section{Outputs}

Source: Author's own source

Figure 1 Work group Inputs and Outputs

\section{Teamwork and its characteristics}

Group work is of great importance; persons who wish to participate in community and professional life must possess the necessary skills to work in team. The group represents two or more members with the same goal, for a certain period of time and for specific field. However, teams are diverse and can appear in many forms.

Culture plays a huge part in the group and the way an organization operates. Organizational cultures have complex relationship with the environment in which they operate and from which they recruit their members (Hatch \& Cunliffe, 2006). People, who tend to join an organization, must have already been socialized by cultural institutions such as family, community and school. Once they become members of an organization, their culturally influenced values, identities and skills combine with those of the organization thereby carrying aspects of national as well as regional, industrial, occupational and professional cultures into the organization.
Three basic skills that each member of one team work should possess and which are necessary for effective teamwork are:

a) Ability of decision-making and planning,

b) Ability of adaptability and flexibility,

c) Ability of interpersonal relations.

Members of one group possess the capability of direct communication and reciprocal cooperation, which connects the common interest (Kume, 2002). We can conclude that a particular characteristic of group is their equal comprehension and approval. These characteristics are essential for the effective functioning of a group including any agreement or harmony between members regarding the issue or objective which seeks to be realized. Forming a group is a sensitive process. As we said, the group may be formed by two or more members, where the maximum number of members is 25 . And how it looks, you can see at the following figure:
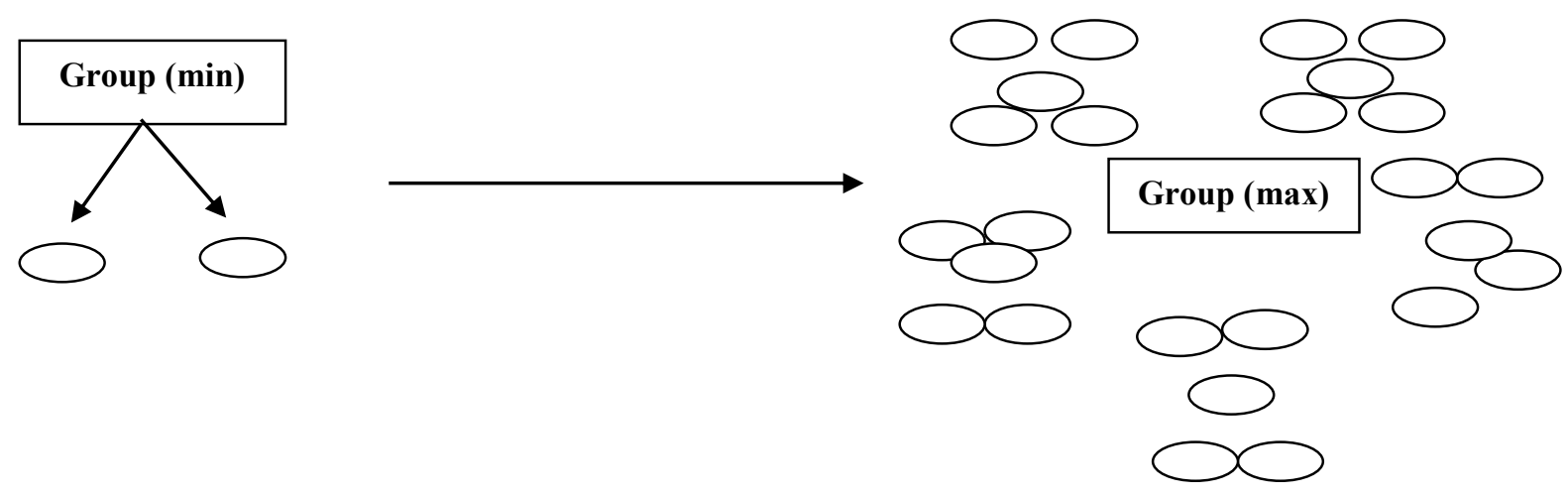

Source: Author's own source

Figure 2 Number of members in different groups 
But we must bear in mind that the functioning of a group depends exclusively on good and qualitative management. Person selections includes: the behavior, attitudes, skills, knowledge, expertise and technological proficiency required and asked for in job holders; these reflect the requirements of the job and work descriptions, and also provide the basis for selection (Pettinger, 2002).

Each member must have below-mentioned elements or characteristics: member who do not weighs only his personal interests, member who is willing to give his best to achieve the objective, member who will participate in each section, member who would share his ideas with others, member who will have the correct communication with everyone, member who will motivate others, member who will be interactive with others, member who shall be an innovator, member who has experience, member who shall take the assistance of members who have difficulties.

\section{Advantages and disadvantages of Teamwork}

Organizational groups are constituted for a purpose, to meet a set of aims and objectives (Pettinger, 2002). It is increasingly common to believe that teamwork has many advantages and that it can increase organizational efficiency and provide competitive advantage. Of course, there are also authors who warn that not all teams have to be successful. Those are teams that are badly managed and that have clearly defined goals and ways to achieve these goals.

Advantages of teamwork are: increase work efficiency, expanding knowledge and skills, greater motivation and satisfaction of team members, increasing organizational flexibility and speed, improving decision-making processes and problem-solving, reducing operating costs, distribution of work, creative activities, brainstorming, controlling work, establishing a self-summary and self-concept, the implementation of initiatives, directions, policies, qualitative strategies and decisions and coordination and harmony...

Disadvantages of Teamwork are: power of pre orientation, changing the system, social Loafing, the tendency for riskier decisions, self-interest, disagreements and conflicts, individual decision-making...

\section{RESEARCH METHODOLOGY}

For the creation of this work I have used qualitative method. Considering that this method involves examining people and their thoughts, I decided to use it out through this work. The aim of using this method applies to general examination of the individual perception of people and collecting all the information necessary for the creation of this paper. Based on this method, I got answers to the questions; why, how, what, where, when...

So that, by this method I have produced information related exclusively to one case study, and that is "Cooperation and Understanding Work Team".

\section{Form of the Questionnaire}

Questionnaire is composed of logical questions, which does not represent the complexity of giving answers. It is simplified with the aim of obtaining simple, correct and logical answers. The whole questionnaire is divided into two parts, where:

I part - includes 10 questions, of which 3 optional and 7 textual. The reason why I have set up more textual questions in this part it is because I wanted to know how close or far the surveyed are familiar with this form of cooperation. This part is dedicated to general implementation of teamwork. In this part the questionnaire included people of different ages and positions. The surveyed were individuals who are within the Faculty of Business, and they are:

1) Academic staff,

2) Administrative staff,

3) I (first) year students,

4) II (second) year students,

5) III (third) year students.

II part - includes 15 questions, divided into $3 \mathrm{sec}-$ tions (personal information, cooperation with other ethnicity, general perception of cooperation process). This part is dedicated to the implementation of the cooperation process only between students with different ethnicity in the territory of transition countries - Kosovo. The surveyed were individuals who are within the University "Haxhi Zeka" in Peja, including different faculties, also students of the Faculty of Gjilan, but also secondary schools, etc. 


\section{General results about Teamwork}

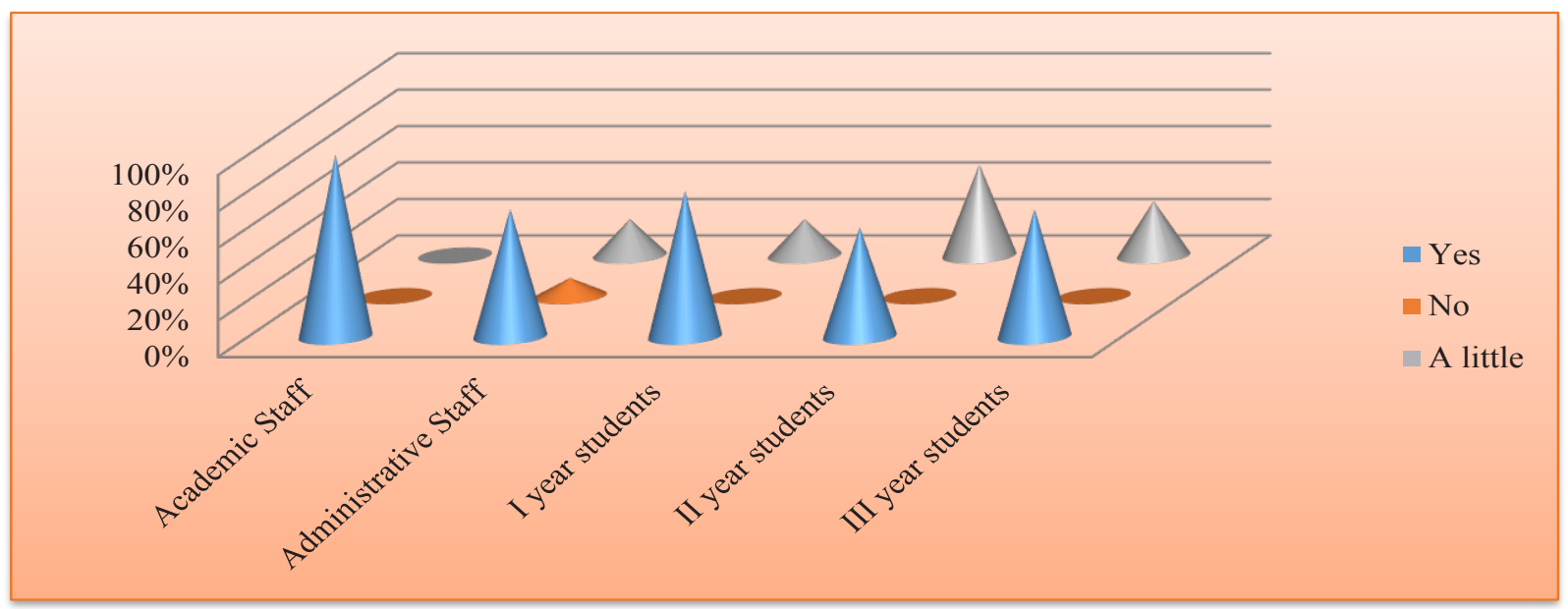

Source: Author's own source

Graph 1 The use of Work Groups for each variable

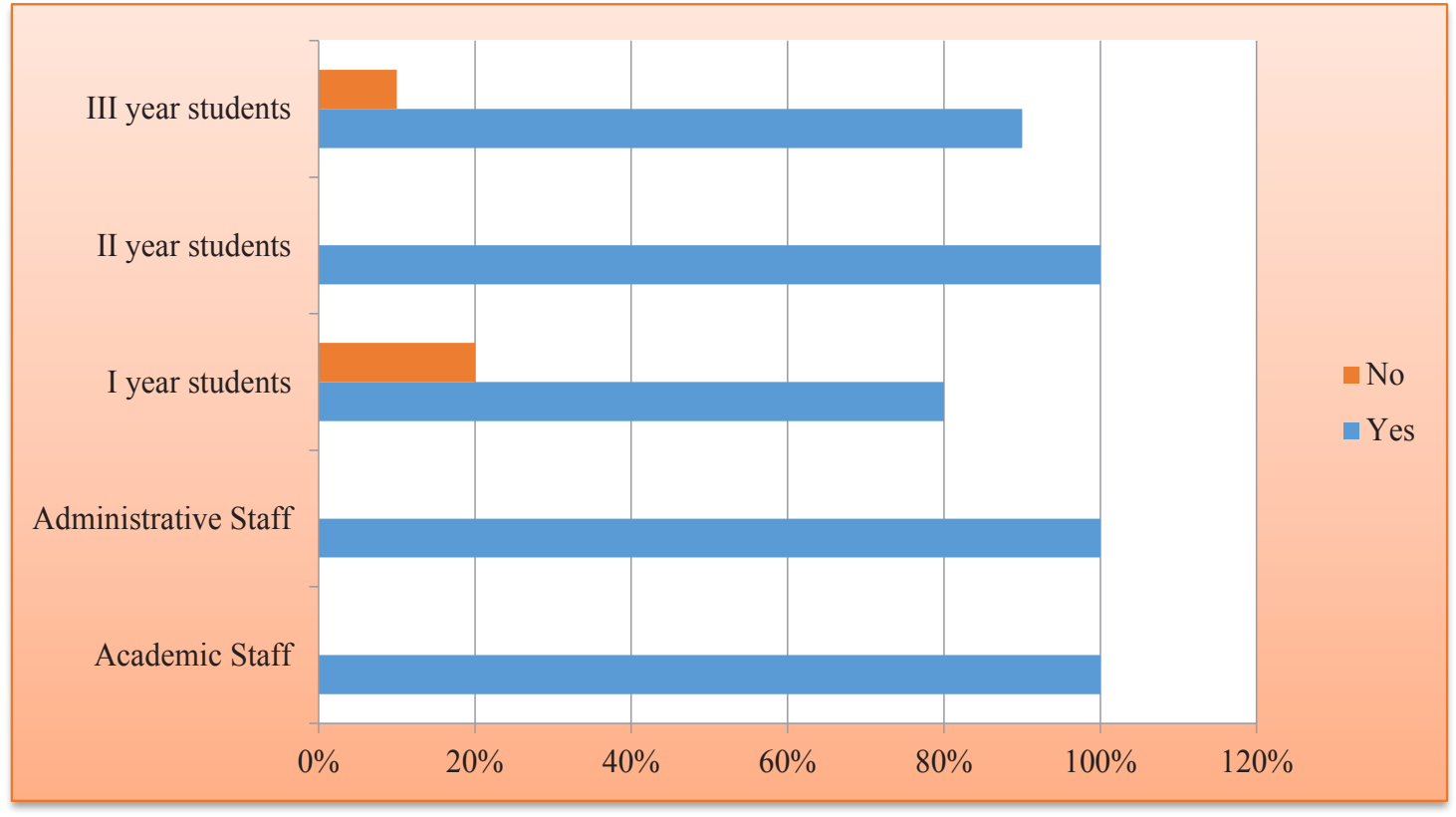

Source: Author's own source

Graph 2 Participation in work team for each variable 


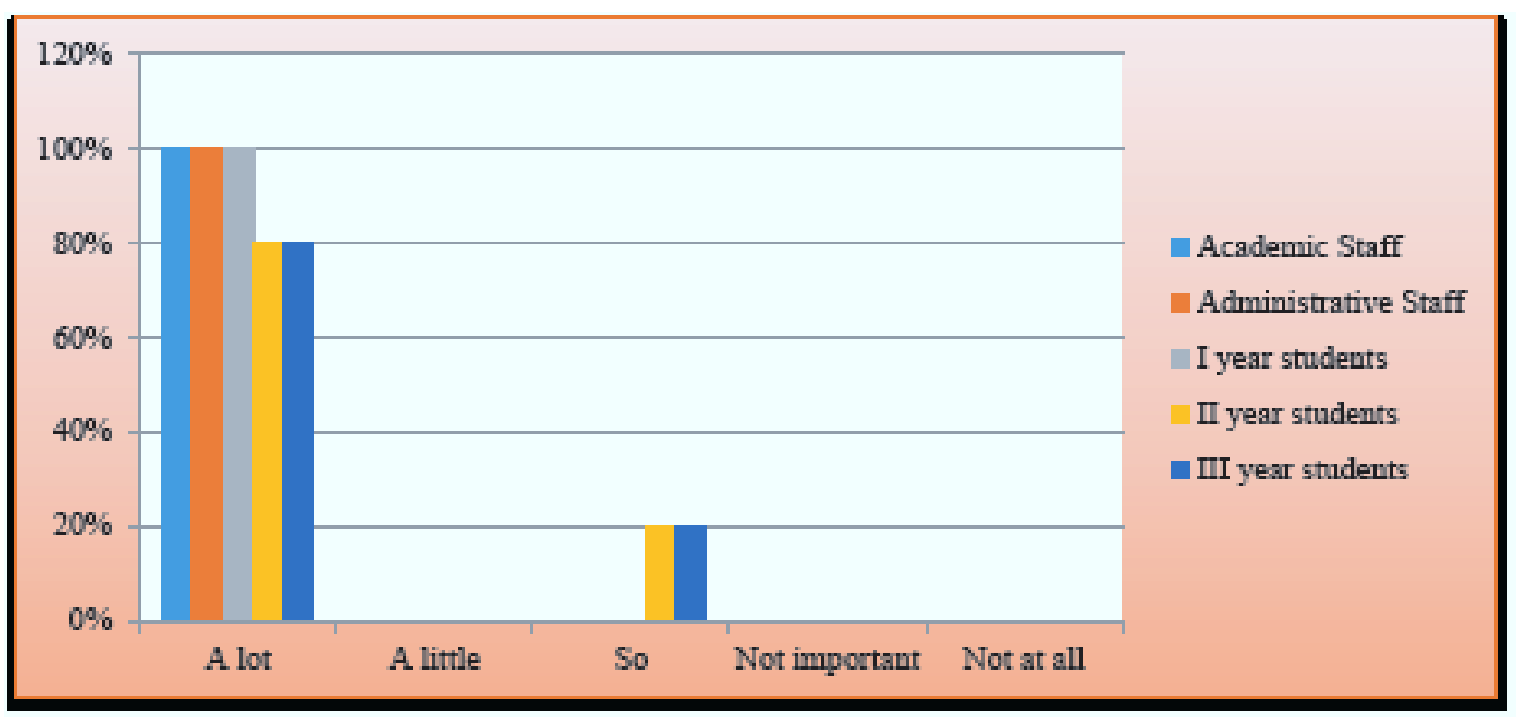

Source: Author's own source

Graph 3 The importance of working in teams for each variable

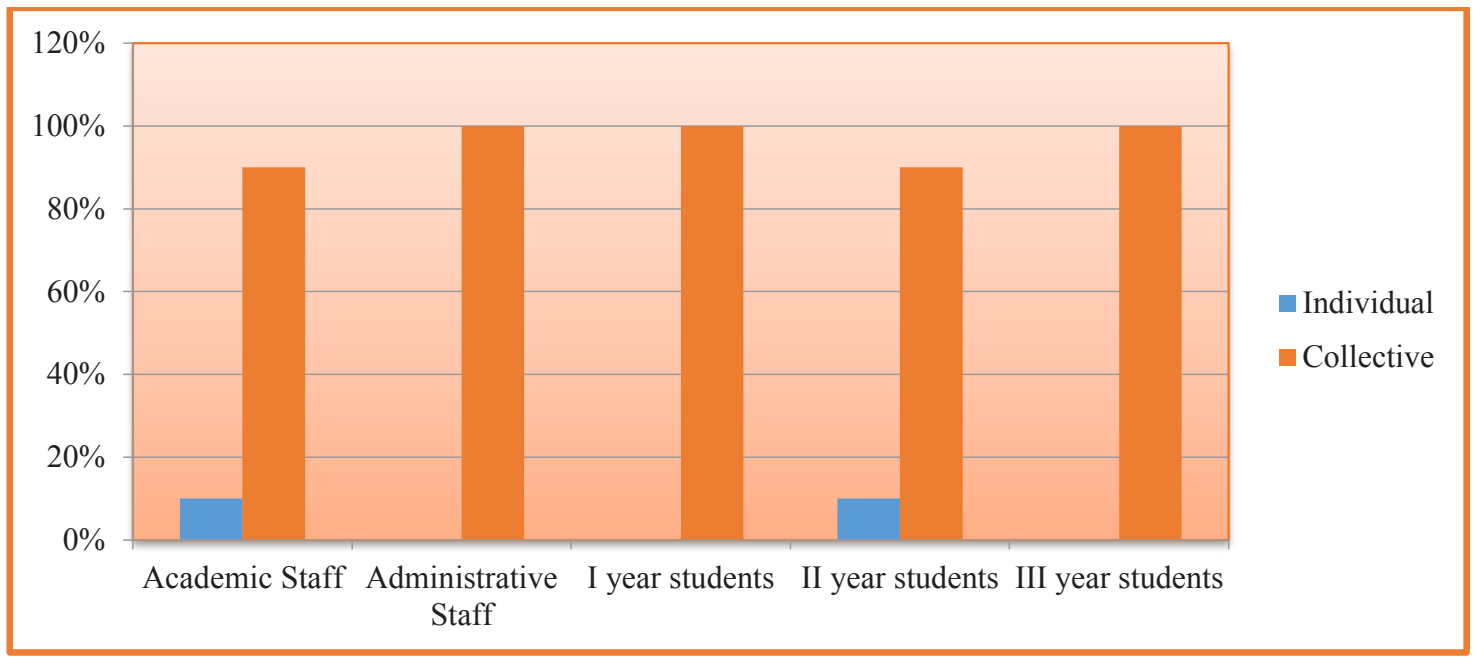

Source: Author's own source

Graph 4 Decisions making for each variable

\section{Academic staff}

People who own a higher level of education and experience have justified their positions. The surveyed staff showed and proved once again that their knowledge level is extremely high. To all questions I have received very concise and logical answers.

They are aware of how important teamwork is for the entire society in Kosovo, especially in our institution. They constantly strive that this form of work should be applied in our institution, simply because the quality, the success and the prosperity of our institution could get a completely different, i.e. better course of management, organization and control over the entire system of the work. They consider that our students should be more involved in this form of work, where through the cooperation joint implementation of the ideas could be reached the prestigious level of knowledge and broader flexibility. At the moment when our society get a clear picture of all the benefits provided by this system of work, they will be activated immediately without a doubt. They have also discovered us that they are constantly trying to join more students into a group on the realization of some academic subject (e.g. Seminar paper). 
There are very few cases of individual works. Usually these are individuals who consider themselves indispensable.

They are aware that this form of cooperation it is not enough implemented in our institutions, but they argue that by using this form, the flexibility of making decisions or solving a specific task would be extremely unbeatable. If we want the level of Teamwork going upwards, many reforms are necessary when it comes to culture and mentality of the people, to the business plan and general. That means that they are aware of the fact that poor implementation of this form of cooperation depends a lot on the culture and mentality of our people. There are many people who consider themselves exceptional and don't want to share their knowledge and success with others. Often happens that some individuals disparage others, simply because they consider themselves worthier or even unique. All in all, academic reforms are necessary.

Positive factors: quality, success, prosperity, cooperation, joint implementation of the idea, prestigious level of knowledge, broader flexibility, management, organization, control.

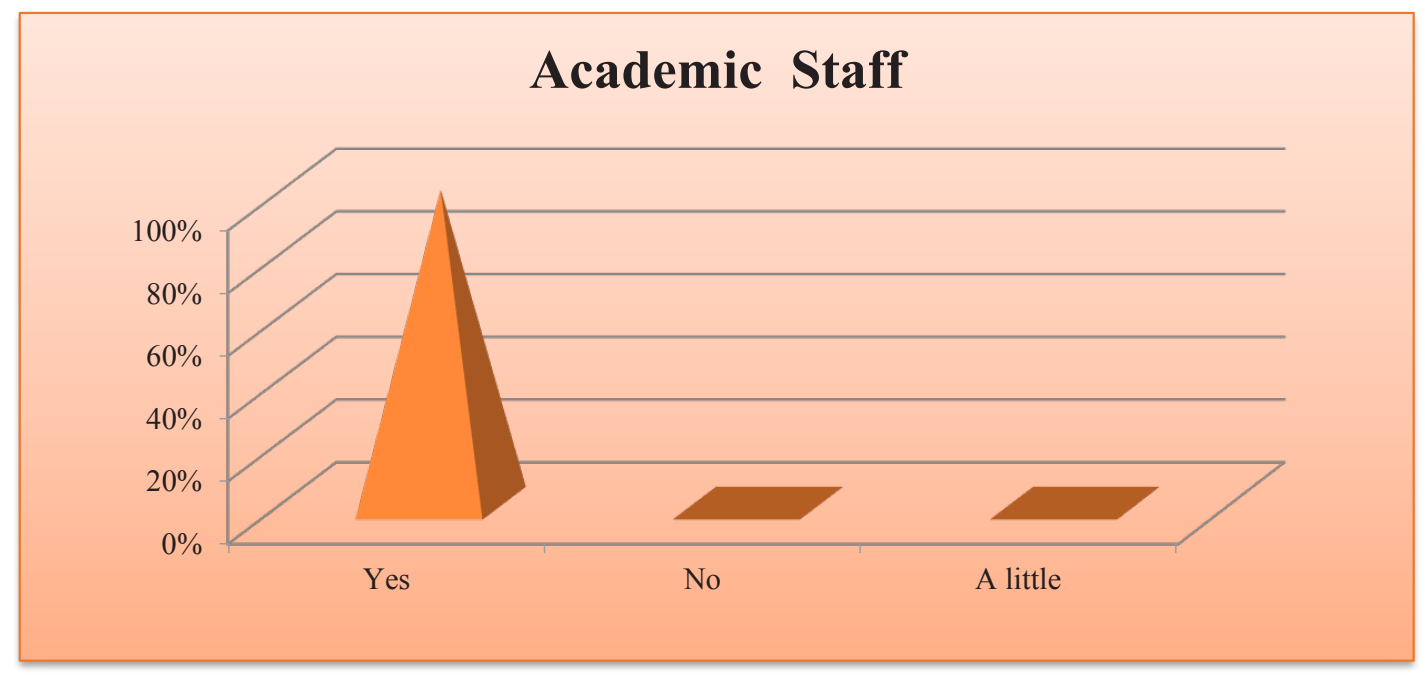

Source: Author's own resource

Graph 5 The use of Work Group

\section{Administrative staff}

Collected information of the surveyed Administrative staff indicates positivity. It is obvious that they are all aware of what constitutes teamwork and how important it is for successful realization of the goals set. The answers were different; however the context was the same, which tells of positive awareness of our administration.

They argue that the Working Group owns more advantages than disadvantages, emphasizing repeatedly: quality, efficiency, effectiveness, stability, rational use of resources, less chance for error, cooperation, more choices, synergy....

However, they say that if members of one group are not collegial than it can come to a conflict of interest, emphasizing and dominance.

They consider that the main key for success is Teamwork, simply because joint decisions have better results, and as one of the main parameters of good communication, is undoubtedly openness to different ideas. According to them, collective decisions have a greater advantage over the individual, stressing repeatedly: better quality, stability, greater impact, better decisions, different ideas, more effective decision... However, individuals who are targeting individual decisions have defined as people who want to: stand out, be more special than others, be in the center of attention, acquire its own success without side impact, have more confidence in their decisions, target their interest. Despite the positive awareness, there are negative effects that prevent the productivity of teamwork. Although they stand behind these actions that are very important and necessary to work in a group, in essence it is very little implemented in Kosovo. 
Most of them have participated in this kind of cooperation and certainly strive to be as much as pos- sible implemented when it comes to high goals and tasks.

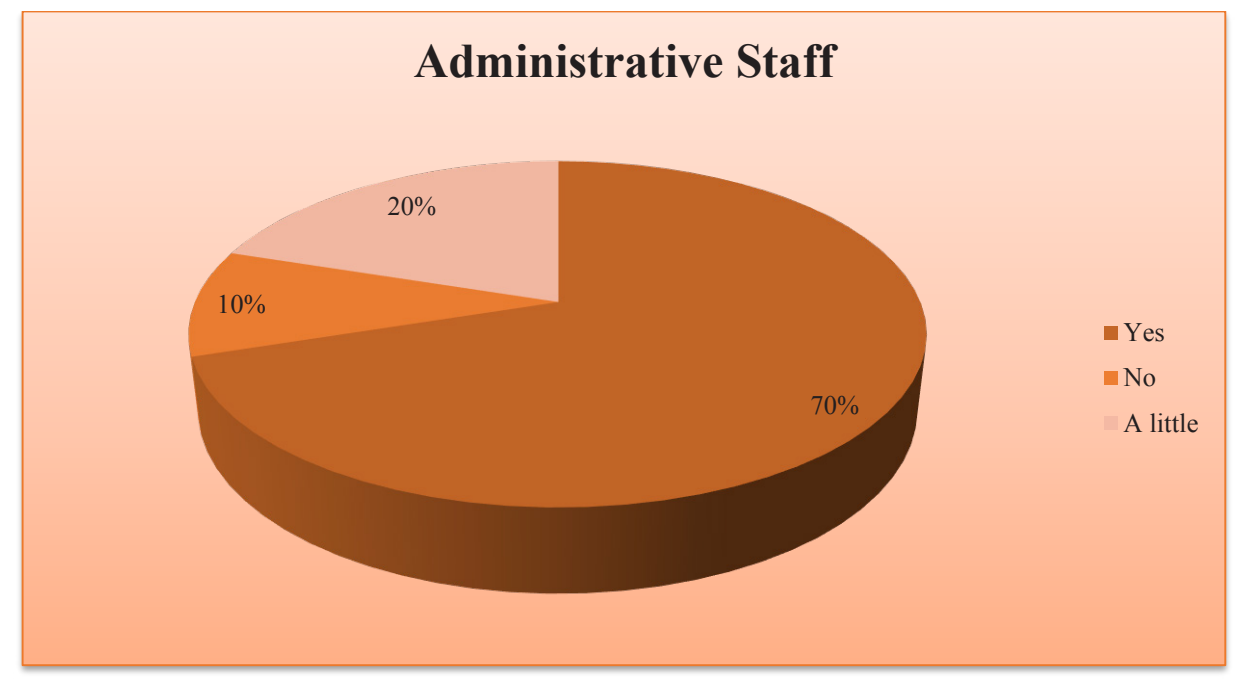

Source: Author's own source

Graph 6 The use of Work Group

\section{I (first) year students}

Although beginners, they have proven very positive energy and knowledge of this type of work. Most of them were participants in this form of work. They have expressed a great satisfaction with it. Reactions and also the results were quiet positive, which have also facilitated my questionnaire. Exceptions are a few disadvantages and dissatisfactions with the performance of some individuals who have tried to dominate. However, most of the decisions were taken by many other people who were joint their interests.

I am very surprised with their answers. Their awareness is very comprehensive, i.e. they have a wide viewing range. They are willing to work, as they say teamwork realizes: organized work, easier achievement of the objectives, the joint of participations, joint decisions, the right for all to present their ideas, better coordination, less responsibility for individuals....

For them there are no disadvantages, as long as members are able and willing to work as a team. So, they consider that before joining the group they must determine their abilities and their interests.

They have intensified, that people who can not or do not want to work in a group think only of their interest, they think they are cleverer, targeting their fame and play just for themselves. Some thinks, that it is easier for some individuals to work independently, i.e. they do not know to work in a group, they feel like more able to make their own decisions then in a team, simply because they do not possess the ability of adaptation and cooperation in groups. So, students claim to have collective decisions more effectively, for the simply reason that there are more exchange thoughts i.e. ideas, where with the multiply ways of thinking leads to better decisions, as they say: "Two heads think well than one"! They believe that this type of cooperation should be used more in our institutions, because according to them, some individuals hesitated to expose their opinion because of the fear to make mistakes and to bear responsibility. As well as for the better functioning of the task, better cooperation, to build better interpersonal relationships, to greater confidence among people. That means, for the students of the first year, the implementation of teamwork is of great importance for their academic improvement. 


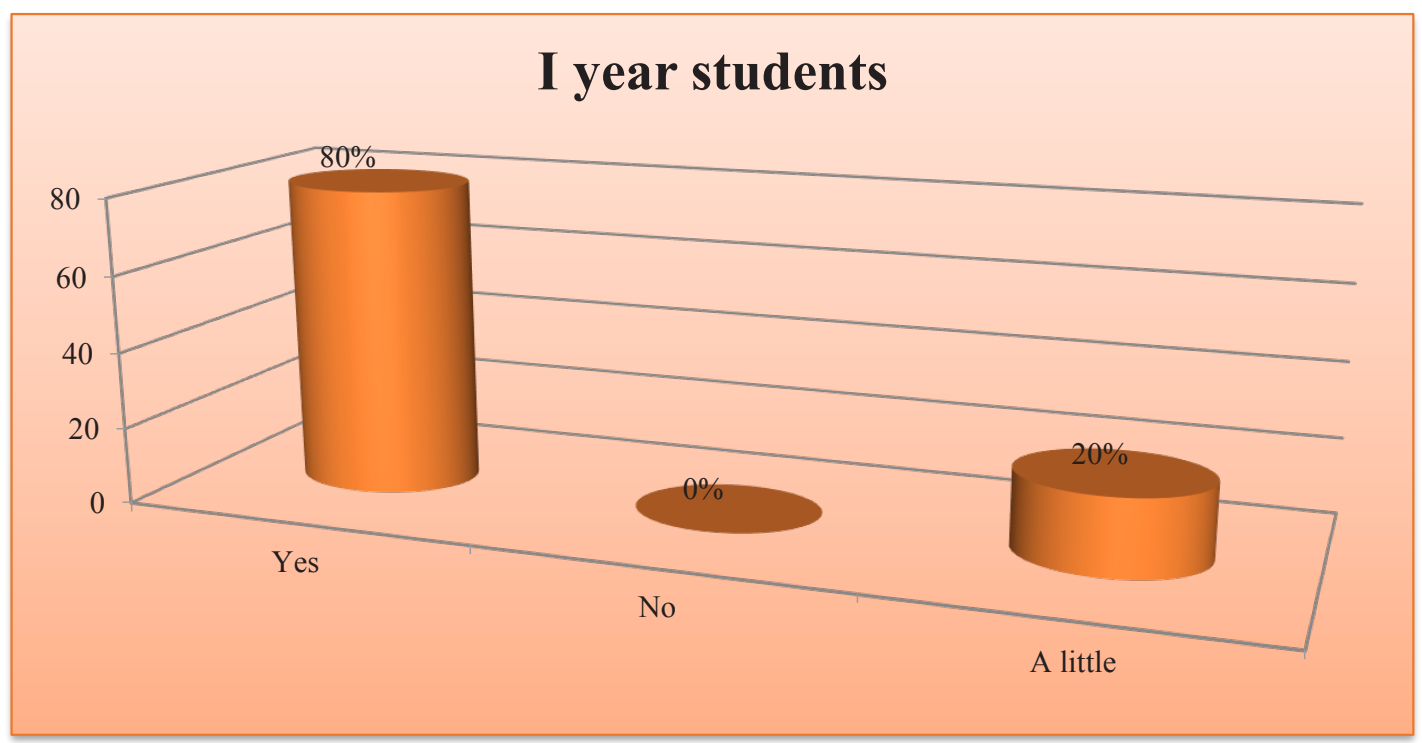

Source: Author's own source

Graph 7 The use of Work Group

\section{II (second) year students}

At each level of higher education understanding of teamwork are more extensive. So that students from the second year have different concept of understanding and viewing from those previous. But of course taking into account that all people are different and have different thoughts, no matter whether they have higher or lower level of education. It doesn't in general play a special role, because there are many people who haven't academic education but they are simply versatile. However, although these students are aware what is Teamwork, there have been some exceptional students who estimated Teamwork with "Like that", that according to them means not much important, but nor irrelevant. From this follows the question, why?
Well, they probably couldn't do well in cooperation with others and became aware that they are more able to make their own decisions. Also the reason may be that the other members were not capable enough to make the right decisions, which led to a dilemma.

Most of them said that if the work group act according to plan and the previous agreement could have a very big impact on the success of achieving the objective. By them Teamwork has a positive spirit where more people can objectively view any situation. There is also something very important that these student have emphasized; deficiency. They said: if one member is irresponsible that can lead to failure of the final results.

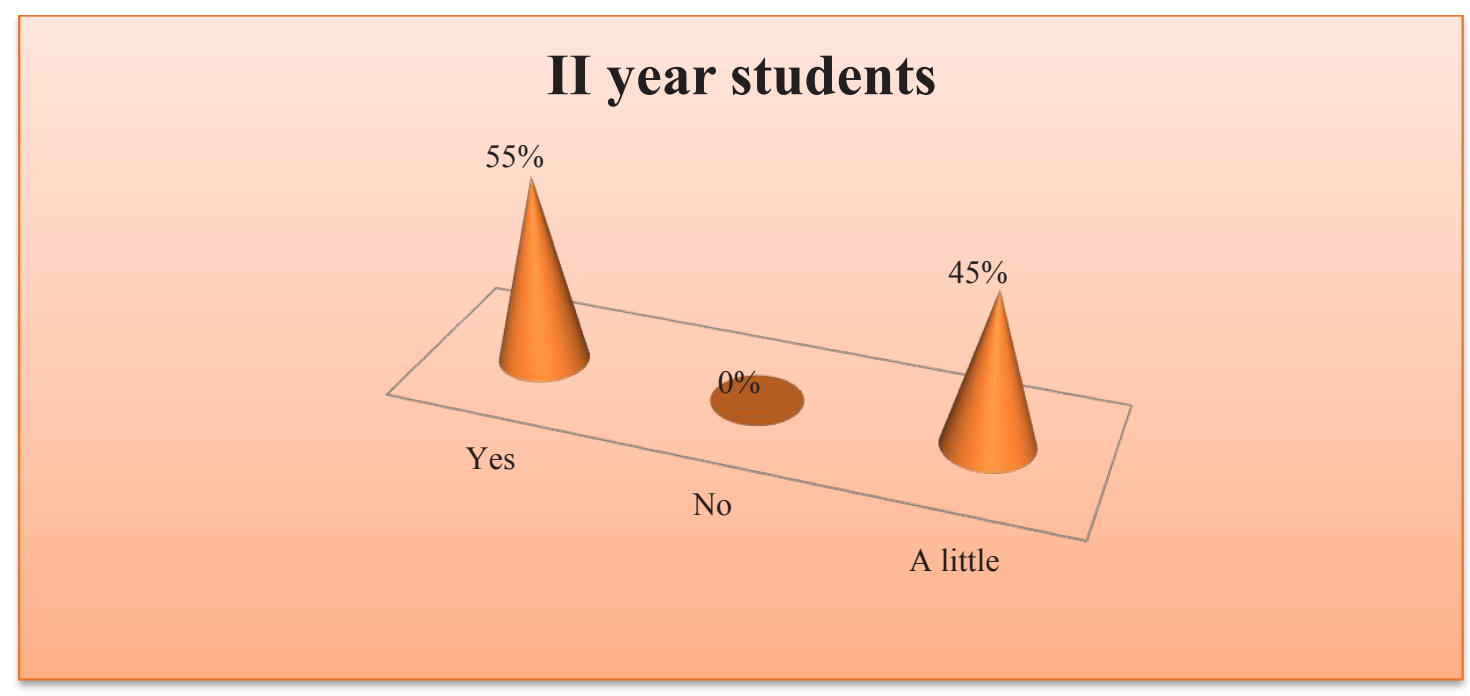




\section{III (third) year students}

This generation have been basing exclusively on the relation professor-student. Through their responses I have found that they feel sufficiently prepared to cooperate in parallel with professors. However, collaboration between professors and students can be exclusively when the student need some advice, instructions, consultation, or even interactivity during lectures. Professors are definitely obligated to explain how what works, but to participate concretely in writing a paper, it would have been superfluous. Simply because professor's work is to evaluate students work not to participate in writing.

In essence understanding teamwork is quiet familiar to them. They have participated in many occasions to this form of cooperation and resolving specific problem. However, I have come across a student who has never participated in a work group, not even in the seminar paper. For it, individual work is far bet- ter than the collective, believing that this form should not be used in the future. However, most of them have given positive answers, which automatically fling in shadow the individuals who oppose. It is interesting the fact that these students have mentioned something that the others didn't, and that is: easier understanding of the material, sharing knowledge and realization of synergy.

These elements, according to them are the most important elements that have a great influence on the success of the implementation results. Otherwise, they point out that people who do not apply collective work, there is a possibility that their individual work could be the lower success and quality. People who do not target teamwork have defined as individuals who tend their own success, satisfying their egos, egoism, and at the end they say that such persons, without doubt, have their personal disadvantages.

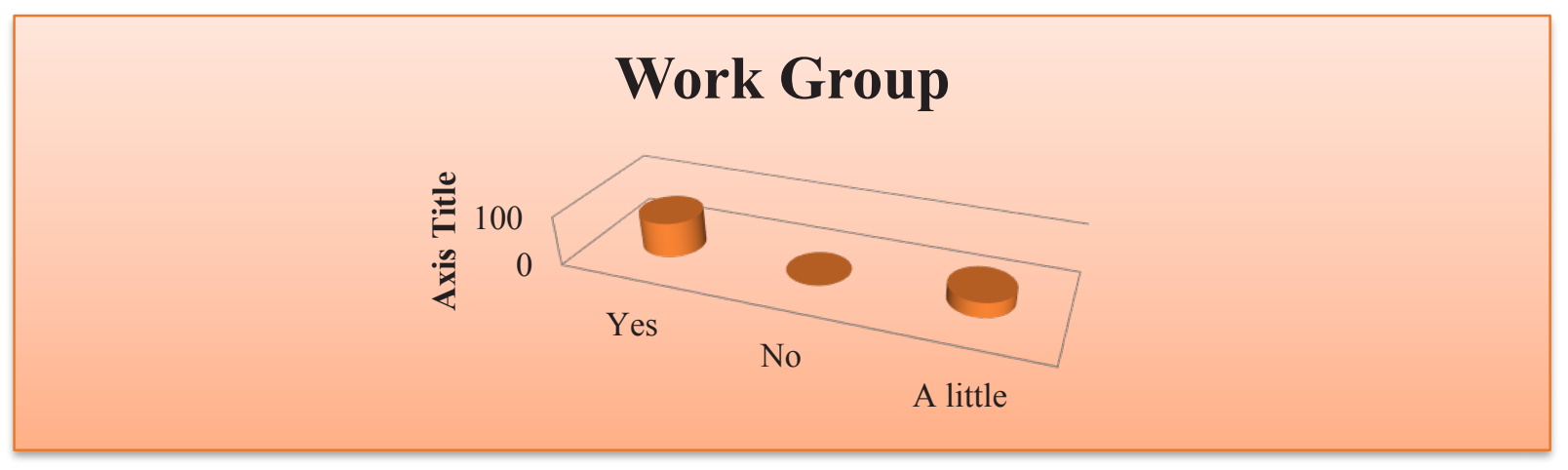

Source: Author's own source

Graph 9 The use of Work Group

\section{Specific results about Cooperation}

This part is dedicated to the specific results about cooperation process between students with different ethnicity in the territory of Kosovo, generally within the faculties. As you can see in the tables below, the surveyed in this part of the questionnaire were 200, where 115 of them were female while 85 male. Most of them were students between 18-24 years old, however there were also those who are older then the previous one. All these information can be seen in the tables and graph below.

Table 1 Respondent's Sex and Age

Respondent's sex

\begin{tabular}{llrrrr} 
& & Frequency & Percent & Valid Percent & Cumulative Percent \\
\hline Valid & Male & 85 & 42,5 & 42,5 & 42,5 \\
& Female & 115 & 57,5 & 57,5 & 100,0 \\
& Total & 200 & 100,0 & 100,0 & \\
\hline
\end{tabular}




\begin{tabular}{cccccc}
\hline & & \multicolumn{4}{c}{ Respondent's Age } \\
& & Frequency & Percent & Valid Percent & Cumulative Percent \\
\hline Valid & $\mathbf{1 8 - 2 4}$ & 166 & 83,0 & 83,0 & 83,0 \\
& $\mathbf{2 5 - 4 0}$ & 30 & 15,0 & 15,0 & 98,0 \\
& $\mathbf{4 1 - 5 1}$ & 3 & 1,5 & 1,5 & 99,5 \\
& $\mathbf{5 2 - 6 0}$ & 1 &, 5 &, 5 & 100,0 \\
& Total & 200 & 100,0 & 100,0 & \\
\hline
\end{tabular}

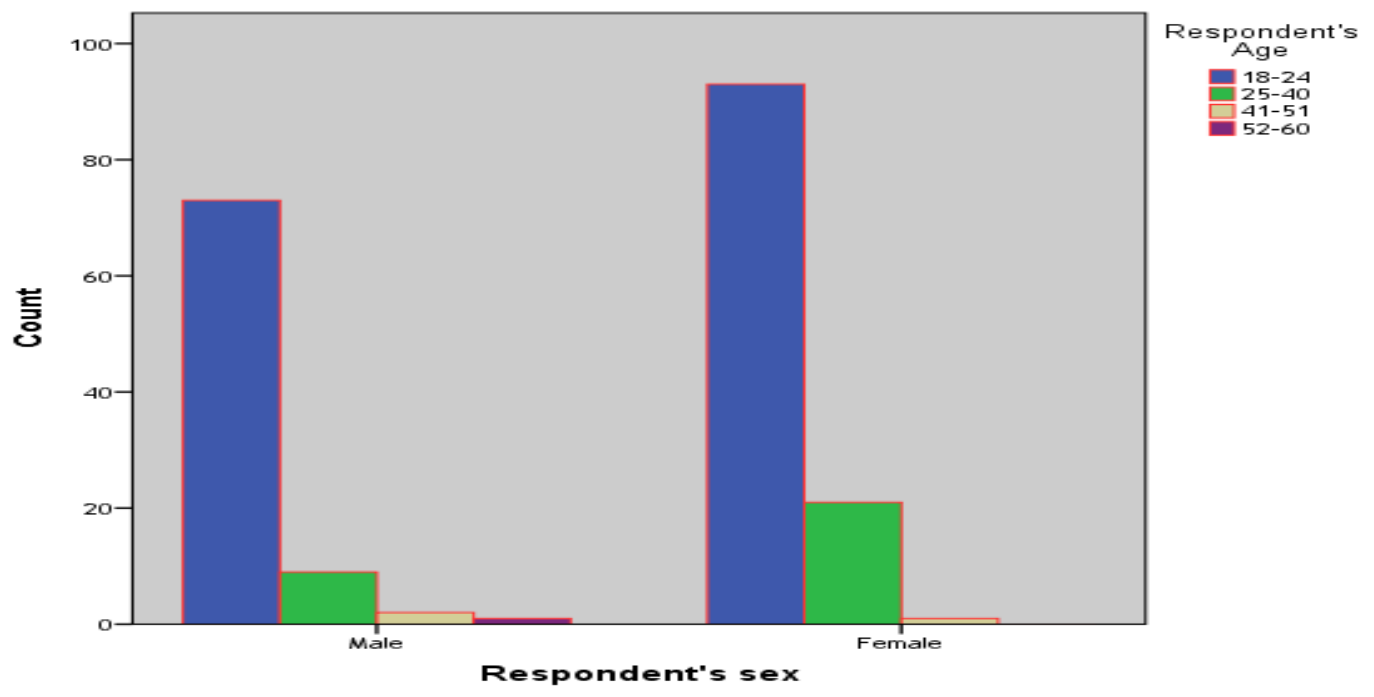

Graph 10. Respondent's Sex and Age

The graph below describes level of education of our when it comes to Bachelor studies, the second place respondent's who belong to different nationalities. takes Bosnians, while the other minor ethnic groups As you can see we have different kind of level edu- have a lower percentage of any of the given educacations, however the Bachelor degree is the most tion levels. Reasons of such low level of education frequent when it comes down to our surveyed. Al- are in fact financial resources, social and culture difbanians are ranked at the top as the leading group ferences.

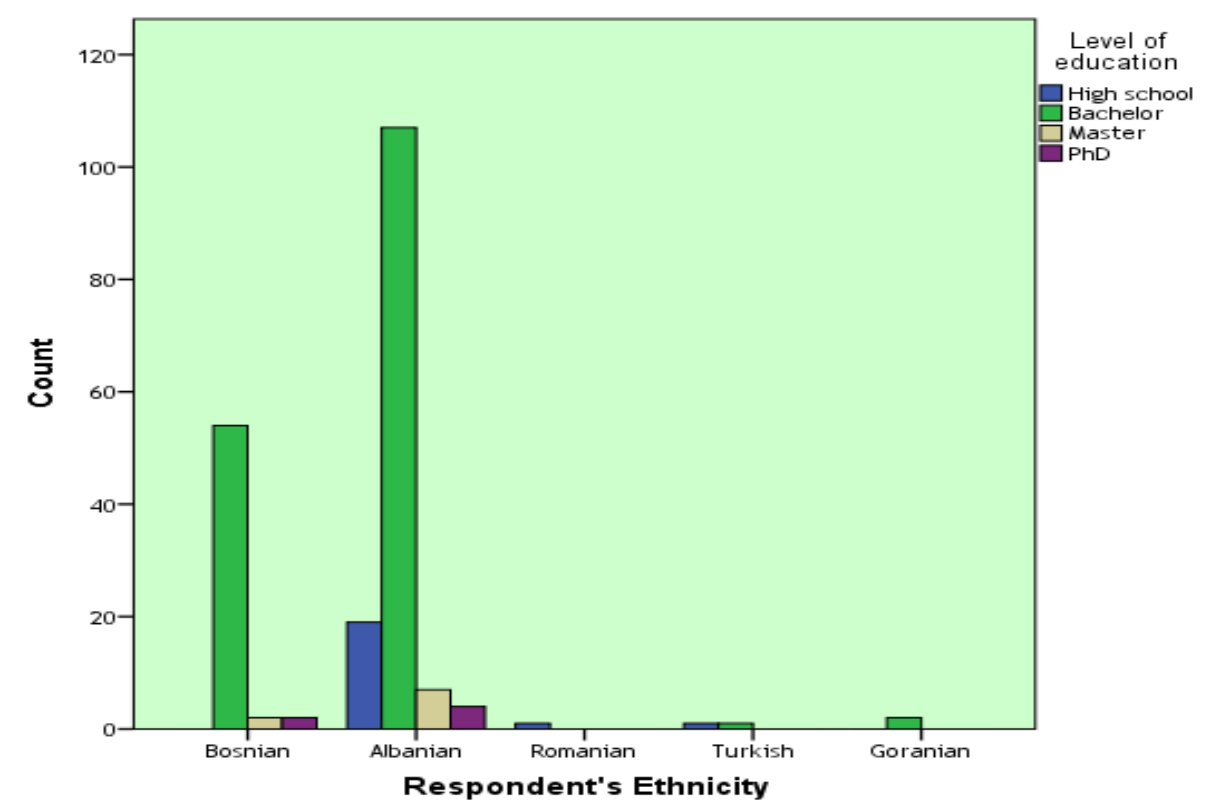

Graph 11 Respondent's level of education 
Even though, all the ethnicity groups are not involved in the education process, there are many of them who have friendships with other ethnicity groups. Major- ity have friendship with different ethnicity groups, while very few of them are not related in friendship to any of community group.

Table 2 Respondent's friendship with other ethnicity

\begin{tabular}{llcccc}
\hline & & \multicolumn{2}{c}{ Other ethnicity friendship } & \\
& & Frequency & Percent & Valid Percent & Cumulative Percent \\
\hline Valid & $\mathbf{0}$ & 1 &, 5 &, 5 &, 5 \\
& Yes & 139 & 69,5 & 69,5 & 70,0 \\
& No & 60 & 30,0 & 30,0 & 100,0 \\
& Total & 200 & 100,0 & 100,0 & \\
\hline
\end{tabular}

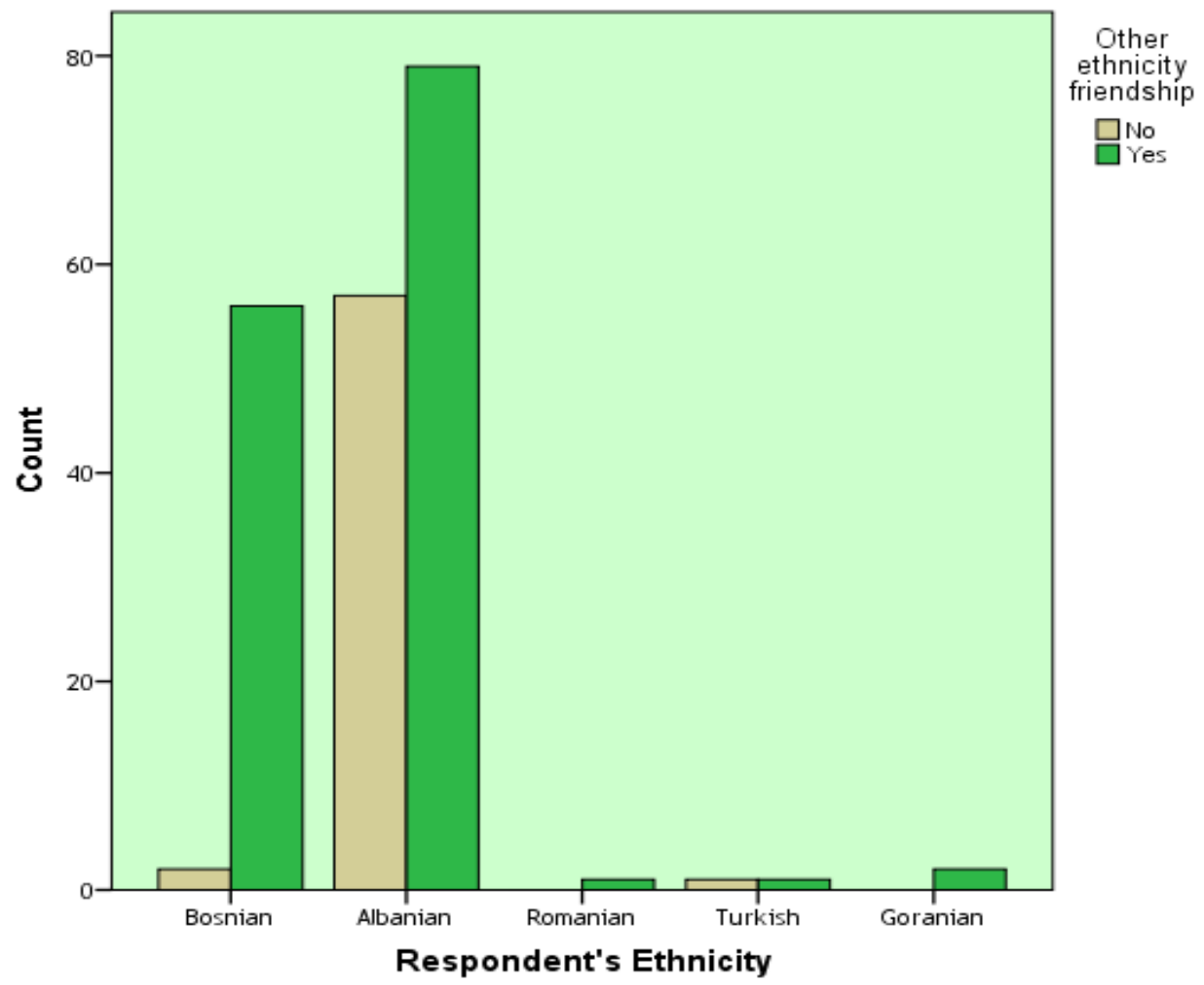

Graph 12 Respondent's friendship with other ethnicity

Many of the surveyed didn't want to respond about the reason why they don't cooperate with other ethnicity groups. But those who have responded specified some of the reasons they do not have friendships with other community groups such as: language, cul- ture differences, religion differences, bus also social differences. We think that all these reasons lie especially on the mentality and the consequences of the after war situation. People are devastating and distrustful! 
Table 3 Reason of don't having friends with other ethnicity

\begin{tabular}{|c|c|c|c|c|c|}
\hline & \multicolumn{5}{|c|}{ Why don't you have friends with other ethnicity? } \\
\hline & & Frequency & Percent & Valid Percent & Cumulative Percent \\
\hline \multirow[t]{6}{*}{ Valid } & Neutral & 141 & 70,5 & 70,5 & 70,5 \\
\hline & Language & 39 & 19,5 & 19,5 & 90,0 \\
\hline & Culture differences & 13 & 6,5 & 6,5 & 96,5 \\
\hline & Religion differences & 4 & 2,0 & 2,0 & 98,5 \\
\hline & Social differences & 3 & 1,5 & 1,5 & 100,0 \\
\hline & Total & 200 & 100,0 & 100,0 & \\
\hline
\end{tabular}

Lack of knowledge about the significance of cooperation had an impact on some of the negative responses and overall condition of some of the respondents. For instance some of them have defined "Friendship with other ethnicity" as weakness or lack! That's totally unac- ceptable, because as long as you are unfriendly and you don't cooperate with somebody, you are punished to the solitude and the possibility of failure. Fortunately, the majority are aware about the significance of the cooperation process, defining it as Advantage and Opportunity.

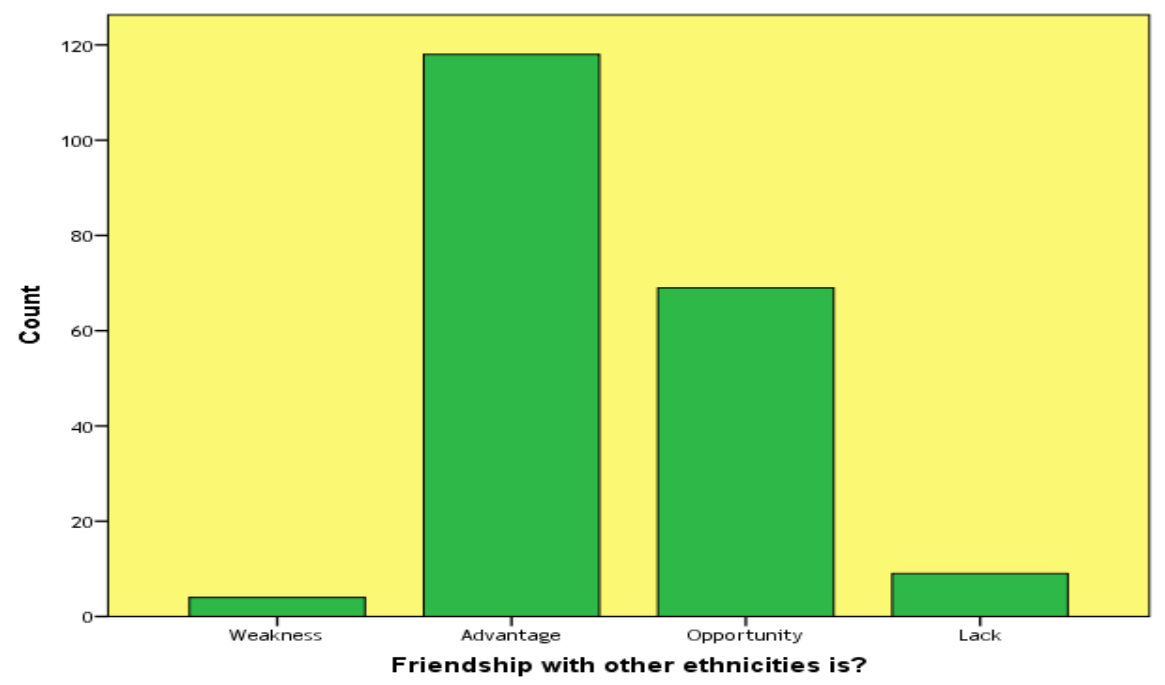

Graph 13 General perception of friendship with other ethnicities

Instead of that, according to the graph below, major- at a higher level. Some of the surveyed do not have ity of Albanians and Bosnians have good professional cooperation with students of other departments. Knowing how this is important, we may expect that this type of cooperation could expand in the future very good professional reports with other, since they do not know the language of each other, but also some of them make many other differences, such as social, culture.... 


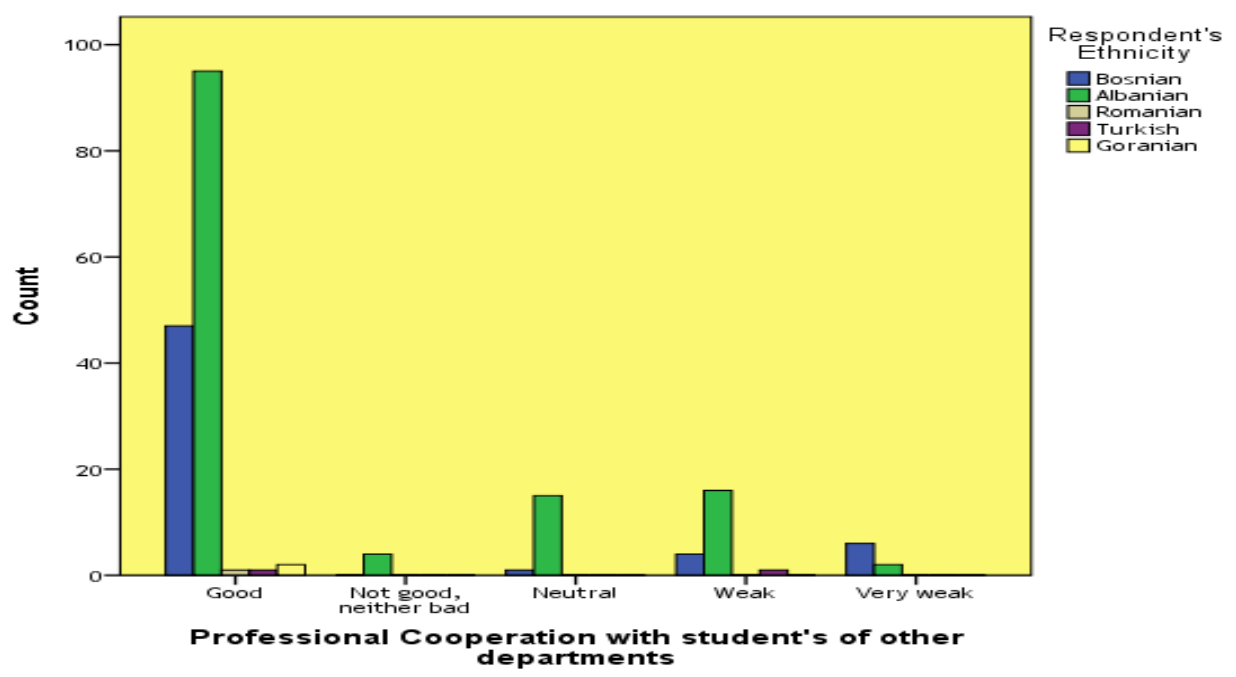

Graph 13 General perception of friendship with other ethnicities

Instead of that, according to the graph below, majority of Albanians and Bosnians have good professional cooperation with students of other departments. Knowing how this is important, we may expect that this type of cooperation could expand in the future at a higher level. Some of the surveyed do not have very good professional reports with other, since they do not know the language of each other, but also some of them make many other differences, such as social, culture....

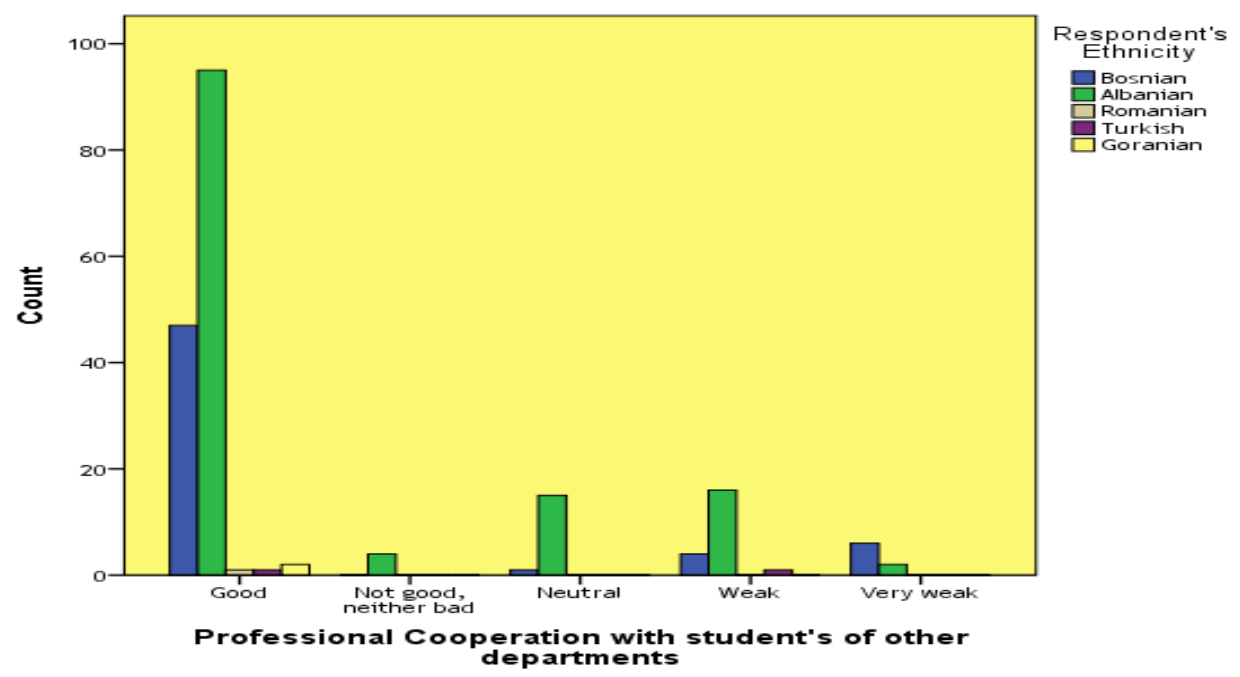

Graph 14 Respondent's professional Cooperation with students of other departments

Surveyed students have different perception and situations when it comes down to the level of cooperation. Many of first (I), second (II) and third (III) year students are on the high level of cooperation with the students of the same ethnicity group but also with those of other groups. There are also those students whose level of cooperation is on the low level, for the same reason we have discussed above. 


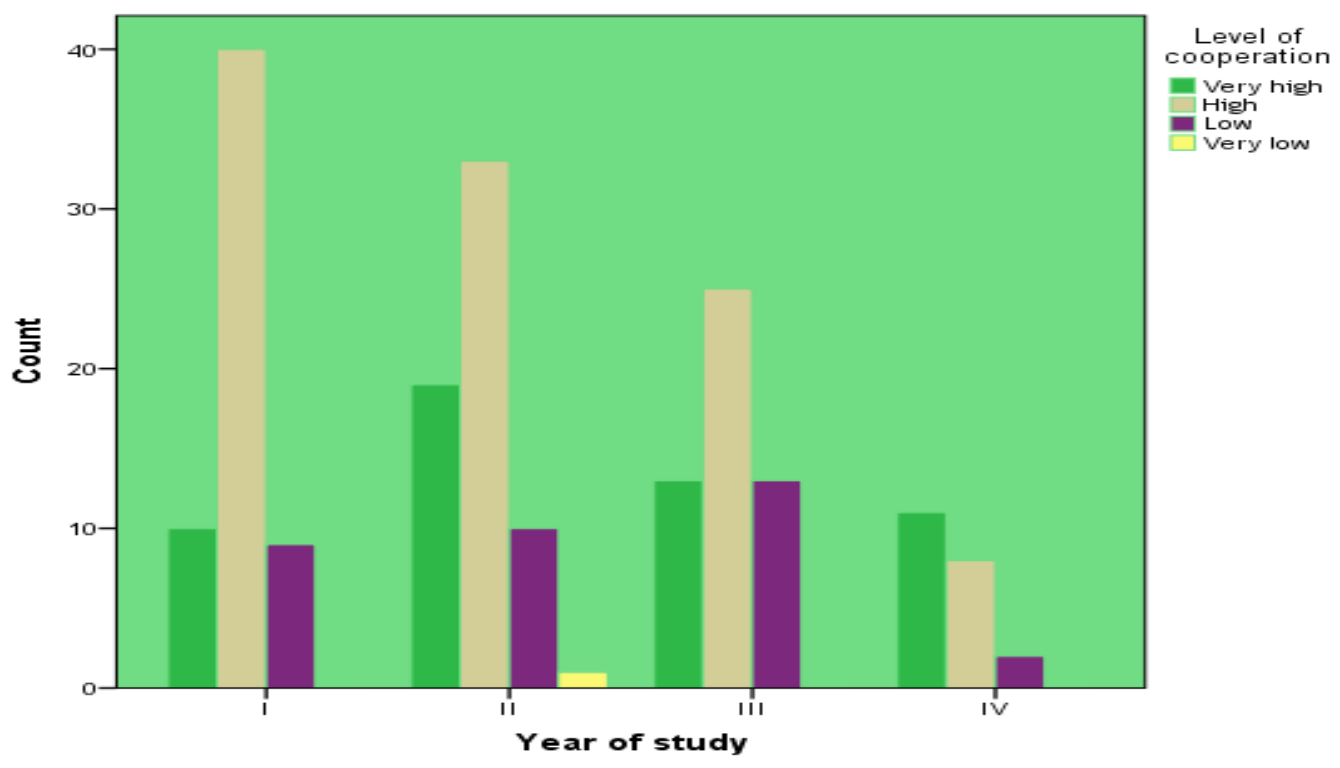

Graph 15 Students level of cooperation

As we can see in the below given graph the most fre- knowledge of languages, but also because they bequent friendship is between Albanians and Bosnians. long within the same University. That's because they are with the same religion and the

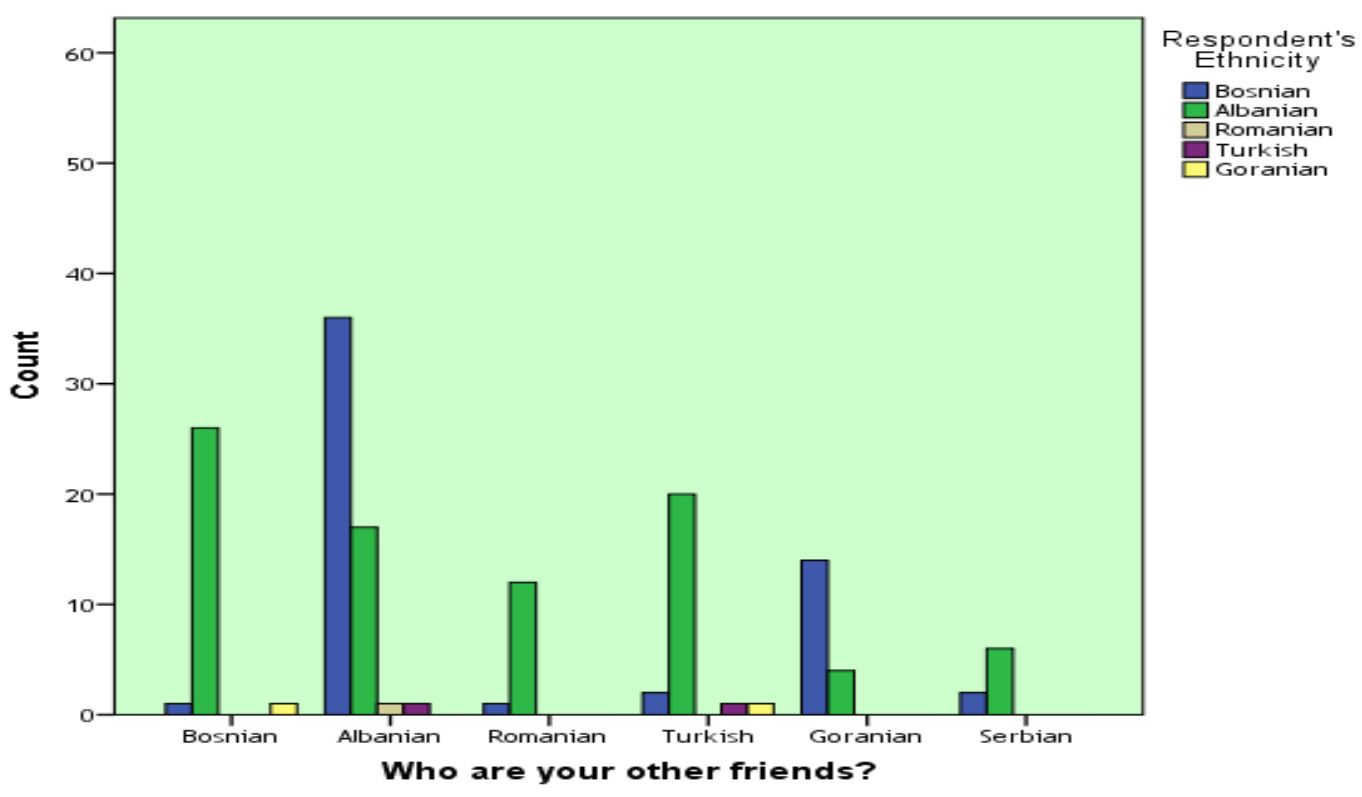

Graph 16 Respondent's friendship

Since we can conclude that the process of cooperation but also the friendship between majority is on the high level, many of them have define themselves with different definitions. Many Albanians and Bosnians think that they can be considered as persons who are ready to help anyone; some of them said that they can cooperate with anyone or can be adopted in any kind of situation. Ethnic groups such as Romanian, Turkish and Goranian have define them- selves just as persons who can be adopted in any kind of situation and persons who are ready to help anyone, but not the persons who can cooperate with anyone. The most important think that they have to be, they are not. According to this, we can say that these groups need to be involved in every kind of interaction and communication, because only in that way they could relive themselves of such negative thoughts. 


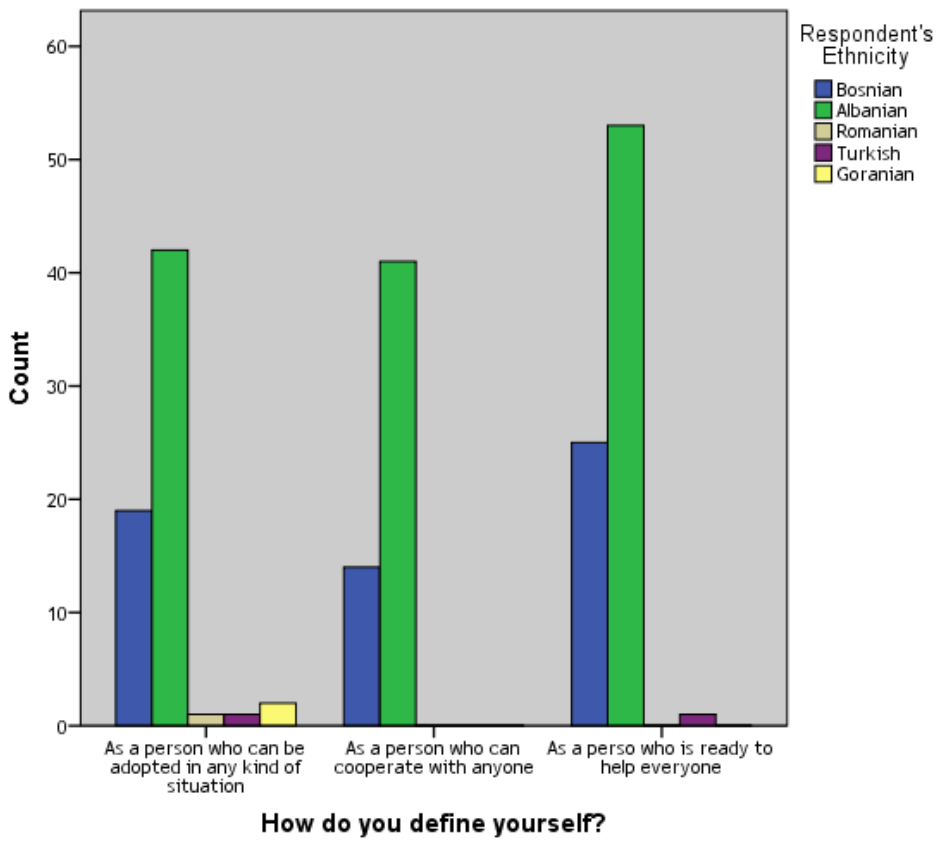

Graph 17 General perception about respondent's

\section{RECOMMENDATIONS AND CONCLUSIONS}

Based on the above mentioned we can conclude that people in Kosovo are not sufficiently aware of the fact that teamwork is one of the key elements of many human successes, both on a professional and personal affairs. Primarily because the decisions that are made with a larger number of people still shows a better and more valuable results in relation to individual decisions.

Majority always can override individuals who aspires a particular purpose without regard for the consequences. So that, when more ideas are explained, one idea has to be the most qualitative and the most effective. Such a final idea, i.e. decision must have something special in itself, i.e. something that the other does not. So that, during making a decision and that final decision must be analyzed in its entirety, it must explain all the advantages and disadvantages that they can carry out, and which can later reflect in a positive or either negative sense. Always "Two heads can think better than one", it was said and confirmed.

However, the formation of teamwork is necessary to choose capable and loyal people. People who know how to work in a group are those people who have an idea and a vision, and people who are willing to im- plement these ideas and visions to the mission without any hesitation and of prejudice. Interviewed have constantly confirmed that teamwork is positive, but the fact that possesses a high quality does not.

I think it would be very useful for our people in Kosovo, especially in Peja, to be motivated by some form of training. Providing hours of teamwork could produce high impact on the progress of business activities. Bearing in mind that the level of science and education is one of the main conditions for joining the EU, and raising awareness of the people would be the same as assisting in developing country.

So that, at the lower level all universities and other institutions should organize special training to see closely the work of the group. Otherwise, the state from the macro level should support not only this form of education, but also all other forms concerning development and improvement. After all, the education is never enough, because as long as man is alive he learns and teaches himself. But, what is important is that we must do our best for our state to succeed in its development and to get out of the transition, and this can be done only when all the ethnic groups establish a bridge of cooperation, teamwork and understanding. 


\section{REFERENCES}

Begg, D., Fischer, S. \& Dornbusch, R. (2000). Economics, Business Organization and behavior, Sixth Edition, USA: McGraw Hill, ISBN 9780077096151

Davis, L., B., Hellervik, W. L. Sheard, L. J. Skube, J. C. \& Gebelein, H. S. (1992). Successful Manager's Handbook, Development Suggestions for Today's Managers, Fourth Edition. USA: Published by Personnel Decisions, Inc, ISBN: 0-9938529-02-1.

Daft, L. R. \& Marcic, D. (2004). Understanding management; Teamwork in Organizations, Fourth Edition. Published in United States of America, ISBN: 0-324-25918-2.

Gareth R. \& Jones, R. G. (2004). Organizational Theory, Design and Change, Fourth Edition, Pearson International Edition, ISBN 0-13-122701-7.

Hubbard, R. L. (2007). The problems of work, Scientology Applied to the Workday World, Denmark: New Era, Copenhagen K, ISBN 978-87-7989-768-7.
Hatch, J. M. \& Cunliffe, L. A. (2006). Organization Theory: Modern, Symbolic, and Postmodern Perspectives, Second Edition, Oxford University Press Publishing

Kume, V. (2002). Marrja e vendimeve menaxheriale, Tirana: Shtëpia Botuese e Librit Universitar, ISBN: 99927-0170-6.

Marcus, A. A. (2005). Management Strategy - Achieving Sustained Competitive Advantage. McGraw-Hill Irwin, ISBN 9780072951875.

Marcouse, I. (2005). Business Studies, Fifth Edition. Italy: Hodder and Stoughton, ISBN 9780340704622.

Mead, R. \& Andrews, G. T. (2009). International Management, Fourth Edition. Published by Wiley, 2009), ISBN: 9781-4051-7399-5.

Pettinger, R. (2002). Introduction to Management, Third Edition, Published by Palgrave, ISBN: 0-333-96807-7. 